\title{
Pengelolaan Tata Air Lahan Pertanian Rawa Pasang Surut Sebagai Upaya Melestarikan Lingkungan Di Desa Mulya Sari Kecamatan Tanjung Lago Kabupaten Banyuasin
}

\author{
Helfa Septinar dan Mega Kesuma Putri
}

Masuk: 04102018 / Diterima: 28112018 / Dipublikasi: 31122018

(c) 2018 Fakultas Hukum dan IImu Sosial UNDIKSHA dan IGI

Abstract Tidal swamps are land that has the potential to be managed as agricultural land in Mulya Sari Village, a village that is in the tidal area. The purpose of this study was to analyze the management of tidal swamp agricultural land in an effort to preserve the environment in Mulya Sari village, Tanjung Lago, Banyuasin Regency. The study was conducted from May to August 2018. The method used was Field Observation, which is direct measurement in the field. Data is presented in the form of graphs and narratives and analyzed descriptively. The results showed that water management in tidal swamp farming as an effort to preserve the environment are: water management through the SPD channel (rural channel), Tertiary, Quaternary, with groundwater level measurements, channel water level and water management during the planting preode. The results of calculating the channel water level and ground water level never exceed the base of the water level, then the availability of plot water according to the needs and cropping patterns adjusted to the time period of water availability. With this management tidal swamp land in Mulya Sari village can increase its productivity, it can also preserve soil fertility so that sustainable agriculture can be achieved.

Keywords: Water Management; Tidal Land; Environmental Conservation Efforts

Abstrak Rawa pasang surut merupakan lahan yang berpotensi dikelolah sebagai lahan pertanian Desa Mulya Sari merupakan desa yang berada wilayah pasang surut. Tujuan penelitian ini adalah untuk menganalisis pengelolaan tata air lahan pertanian rawa pasang surut sebagai upaya untuk melestasikan lingkungan di desa Mulya Sari kecamatan Tanjung Lago Kabupaten Banyuasin. Penelitian dilaksanakan pada bulan Mei hingga Agustus tahun 2018. metode yang digunakan adalah Observasi Lapangan yaitu pengukuran langsung dilapangan. Data di sajikan dengan bentuk grafik dan narasi serta dianalisis secara deskriptif. Hasil penelitian menunjukkan bahwa pengelolaan tata air dilahan pertanian rawa pasang surut sebagai upaya melestarikan lingkungan adalah : pengelolaan tata air melalui saluran SPD (saluran pedesaan), Tersier, Kuarter, dengan pengukuran muka air tanah, muka air saluran dan pengaturan tata air selama preode tanam. Hasil perhitungan tinggi muka air saluran dan muka air tanah tidak pernah melebihi dasar elevasi muka air, maka ketersedian air petak lahan sesuai dengan kebutuhan dan pola tanam disesuaikan dengan periode waktu ketersedian air. Dengan pengelolaan tersebut lahan rawa pasang surut di desa Mulya Sari dapat meningkatkan produktifitasnya juga dapat melestarikan kesuburan tanah sehingga pertanian berkelanjutan (sustainable agricultural) dapat dicapai.

Kata kunci: Pengelolaan Tata Air; Lahan Pasang Surut; Upaya Pelestarian Lingkungan

\section{Pendahuluan}

Luas lahan rawa di Indonesia diperkirakan mencapai 33 juta hektar yang terdiri dari 20 juta hektar lahan rawa pasang surut dan 13 juta hektar lahan rawa non-pasang surut. Dari luasan tersebut, total lahan rawa yang telah dikembangkan pemerintah kurang lebih

Helfa Septinar dan Mega Kesuma Putri Universitas PGRI Palembang helfa23@yahoo.com
1,8 juta hektar, terdiri dari 1,5 juta hektar lahan rawa pasang surut dan 0,3 juta hektar lahan rawa non-pasang surut (Ngudiantoro, Pawitan, Ardiansyah, Purwanto, \& Susanto, 2009)

Pemerintah Indonesia sejak tahun 1970-an telah mulai mengembangkan lahan rawa melalui program transmigrasi untuk perluasan areal pertanian dalam menunjang produksi tanaman pangan terutama padi. Hal ini dilakukan untuk memenuhi kebutuhan pangan akibat 
peningkatan jumlah penduduk yang relatif cepat dalam (Puspiastuti, 2012)

Desa Mulya Sari Tanjung Lago merupakan salah satu daerah transmigrasi yang berada di Kabupaten Banyuasin Sumatera Selatan. Mulya Sari menjadi daerah trasmigrasi sejak tahun 1980. Pada awal dibukanya trasmigrasi masih berupa hutan dan banyak orangorang yang bertransmigrasi di desa Mulya Sari masih mengalami kesulitan dalam mengelola lahannya. Dan beberapa tahun kemudian barulah mulai dikelola seperti pembuatan kanal-kanal oleh pemerintah guna untuk mengelola tata air di lahan yang dijadikan sebagai lahan pertanian.Desa Mulya Sari adalah desa yang berada di lahan rawa yang berada di daearah pasang surut.

(Balai Besar Penelitian Tanaman Padi, 2016)Pengelolaan tata air makro dan mikro merupakan faktor penentu keberhasilan pengelolaan lahan pasang surut. Pengelolaan air makro ini bertujuan untuk membuat lebih berfungsi: Jaringan drainase - Irigasi, kawasan tampug hujan. Sedangkan pengelolaan air mikro, pengaturan tata air di tingkat petani. Adapun tujuan dari penelitian nin adalah bagaimanna pengololaan tata air lahan pertanian rawa pasang surut sebagai upaya untuk melestarikan lingkungan di desa Mulya Sari Kecamatan Tanjuk lago Kabupaten Banyuasin.

\section{Metode}

Penelitian dilakukan di lahan pertanian rawa pasang surut dan berada di desa Mulya Sari kecamatan Tanjung Lago Kabupaten Banyuasin. Penelitian ini menggunakan metode Observasi dengan melakukan pengukuran-pengukuran yang diperlukan langsung dilapangan dan untuk tata cara pengelolaan air dan pola tanam pada budidya pertanian yaitu dengan cara wawancara kepada petani yang dijadikan sebagai responden yaitu dengan menggunakan kuisioner. Data yang di gunakan adalah data primer dan data skunder. Data disajikan dalam bentuk grafik dan narasi dan dianalisis dengan deskriptif.

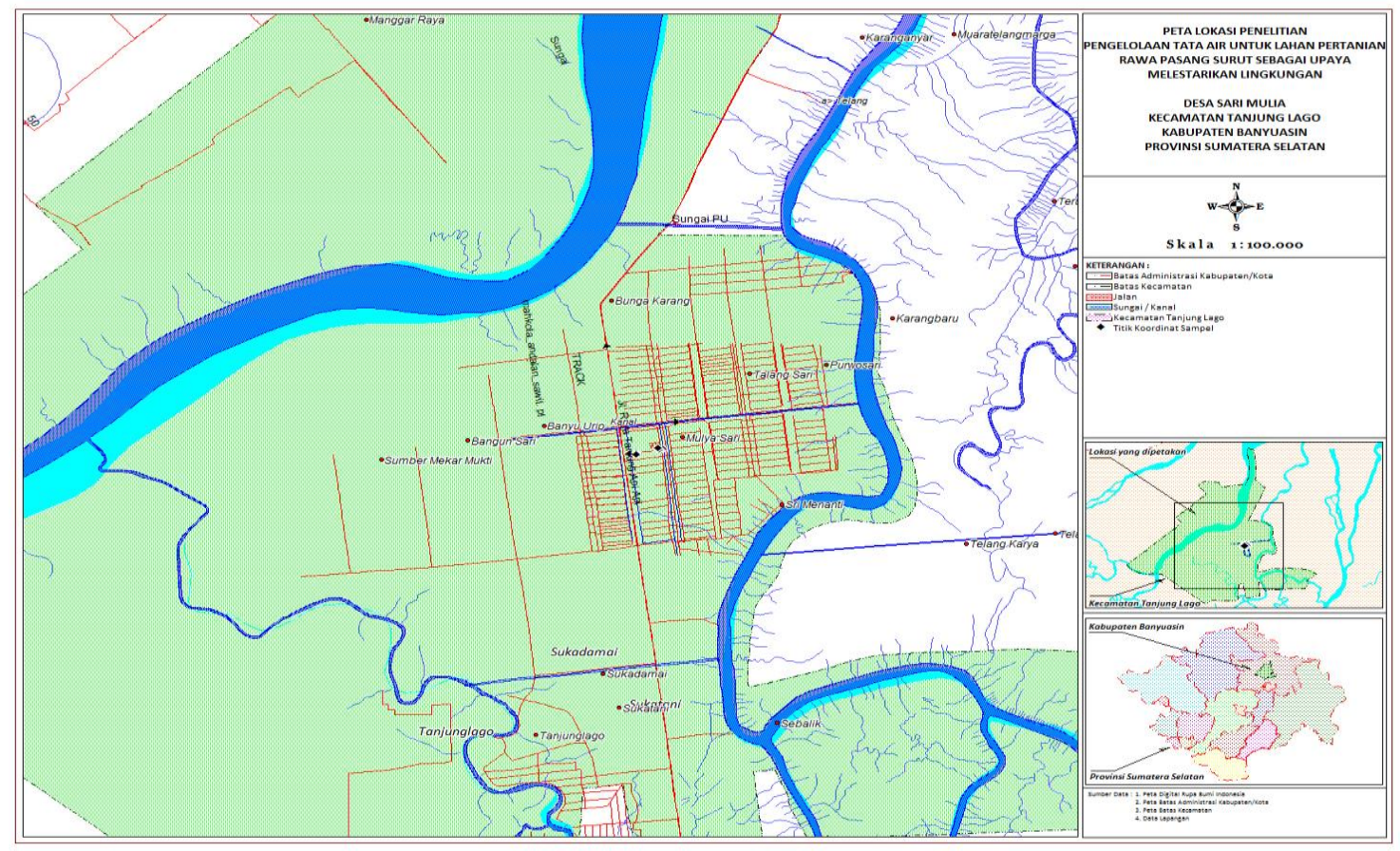

Gambar 1. Lokasi Penelitian 


\section{Hasil dan Pembahasan Pengelolaan tata air}

Pengelolaan Tata Air di desa Mulya Sari adalah melalui saluran pedesaan (SPD), saluran Tersier dan saluran cacing (saluran Kuarter). Pengelolaan tata air dilahan pasang surut gunanya untuk menjaga agar muka air di saluran maupun dipetak lahan dapat memenuhi kebutuhan tanaman, terpenuhi atau tidak kebutuhan air karena dapat mempengaruhi pertumbuhan tanaman tersebut.

\section{Fluktuasi muka air di saluran dan muka air petak lahan}

Untuk mengetahui tinggi rendah muka air saluran, pengamatan dan pengukuran dilakukan di Saluran Pedesaan (SPD) dan saluran Tersier. Pengukuran disaluran ini dilakukan tiga titik yaitu pertama disaluran SPD melalui pielscall SPD satu titik dan untuk saluran tersier di lakukan dua titik yaitu pengukuran di pielscall 1(Pielscall titik ke 1) berada berdekatan dengan pintu air saluran Tersier yang pertama, titik pielscall 2 ( pielscall titik ke 2) saluran tersier bagian ujung. Berdasarkan hasil pengukuran muka air di saluran tetinggi dan terendah di SPD adalah $-57 \mathrm{~cm}$ dan $153 \mathrm{~cm}$, untuk tinggi rendah muka air di saluran Tersier Pielscall titik 1 adalah $64 \mathrm{~cm}$ dan $-95 \mathrm{~cm}$ dan untuk pielscall titik 2 muka air tertinggi dan terendah adalah $110 \mathrm{~cm}$ dan $-60 \mathrm{~cm}$.

Berdasarkan pengukuran pengukuran dasar elevasi muka air saluran di saluran SPD dan dua titik disaluran tersier dalam grafik tersebut menunjukan bahwa muka air saluran tidak pernah berada di atas titik elevasi dasar. Untuk lebih jelas dapat dilihat pada Gambar.2.

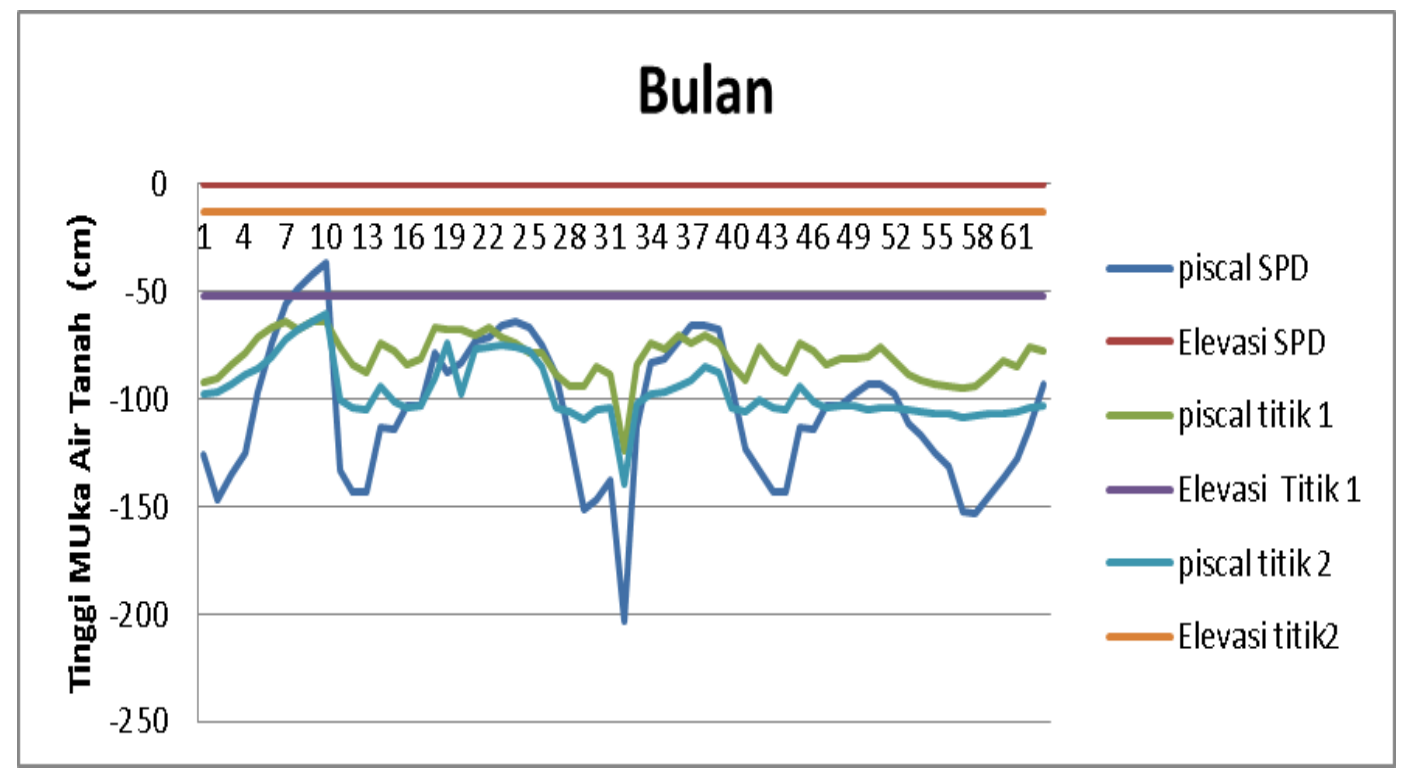

Gambar 2. Grafik Fluktuasi Muka Air Saluran

Sumber: Data Primer, 2018

Hasil pengamatan dan pengukuran muka air di petak lahan bertujuan untuk melihat fluktuasi atau tinggi rendah muka air tanah di masing-masing wells yang berada di titik yang telah ditempat pada petak lahan untuk melihat ketersedian air dilahan pertanian. Wells 1 sampai ke 4 yang menunjukan muka air tanah yang tertinggi adalah sebagai berikut -62, -61, $61,-16$ dan yang menunjukan muka air tanah yang terendah dimasing masing wells 1-4 adalah -101, -110, -90,-80. Pergerakan muka air tanah masing masing wells mulai berangkat naik dari wells1 sampai wells 4 dan sebaliknya. Berdasarkan data yang diperoleh muka air 
tanah tertinggi terjadi di bulan Mei yaitu $16 \mathrm{~cm}$ sedangkan muka air tanah yang terendah terlihat pada bulan Juli yaitu -108 $\mathrm{cm}$ dan $-110 \mathrm{~cm}$ liat ganbar dibawah ini.

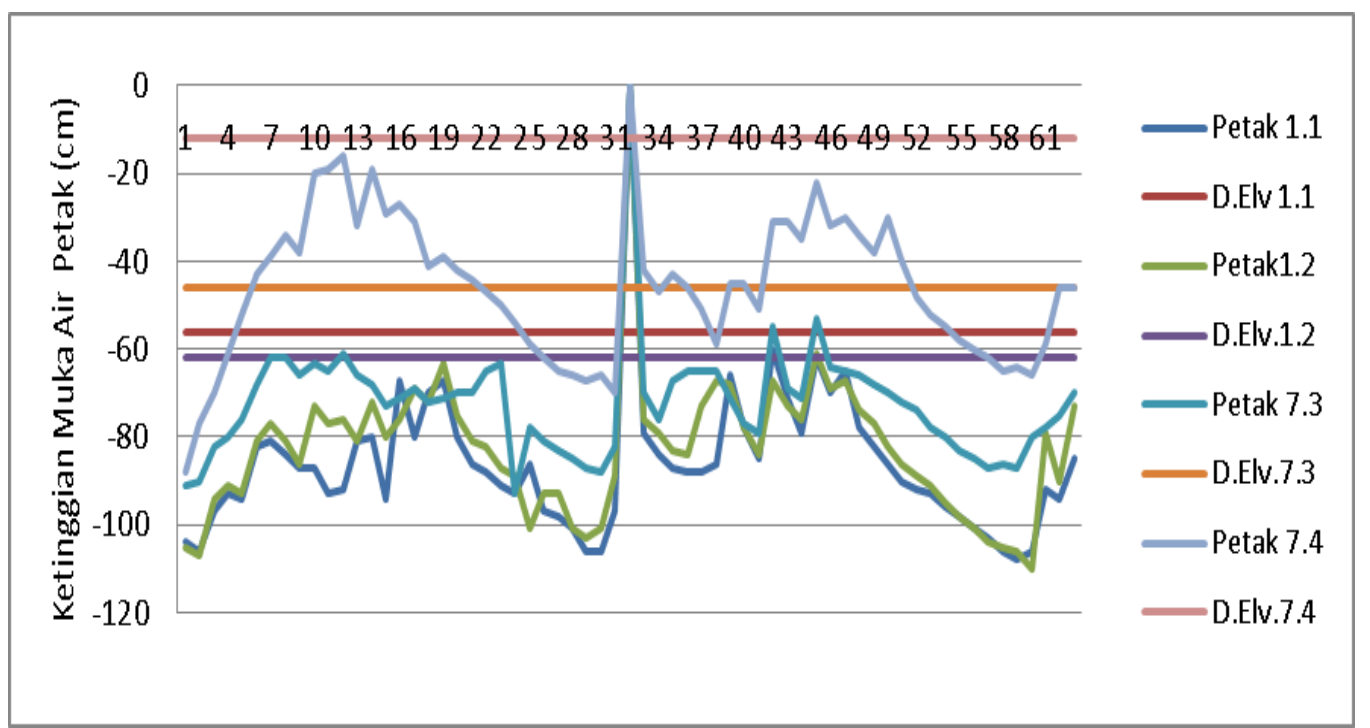

Gambar 3. Grafik Fluktuasi Muka Air Tanah di Petak Lahan

Sumber : Data primer, 2018

\section{Curah Hujan}

Berdasarkan data curah hujan yang di ambil dari BMKG Kenten Palembang bahwa curah hujan dalam tiga bulan yaitu bulan Mei sampai Juli. Curah hujan tertinggi pada bulan Mei dan Juni ada pada bulan Juni curah hujan mencapai $(75 \mathrm{~mm})$ terjadi pada pertengahan bulan Juni dan dalam jangka 3 (tiga) bulan hanya satu hari ini curah hujan tinggi dibandingkan hari-hari yang lain. Namun untuk pembandingan dalam waktu 1 tahun bulan Mei - Juli ini tercatat rendah. Dan dalam kurun waktu tiga bulan yaitu bulan Mei, Juni dan Juli curah hujan yang cukup rendah yaitu pada bulan Juli. Dalam dua bulan yaitu bulan Mei dan Juni curah hujan tercatat masih dibilang banyak bila dibandingkan bulan Juli, tercatat paling sedikit curah hujan yaitu hanya tercatat 6 hari. Gamabr 3 menggambarkan curah hujan.

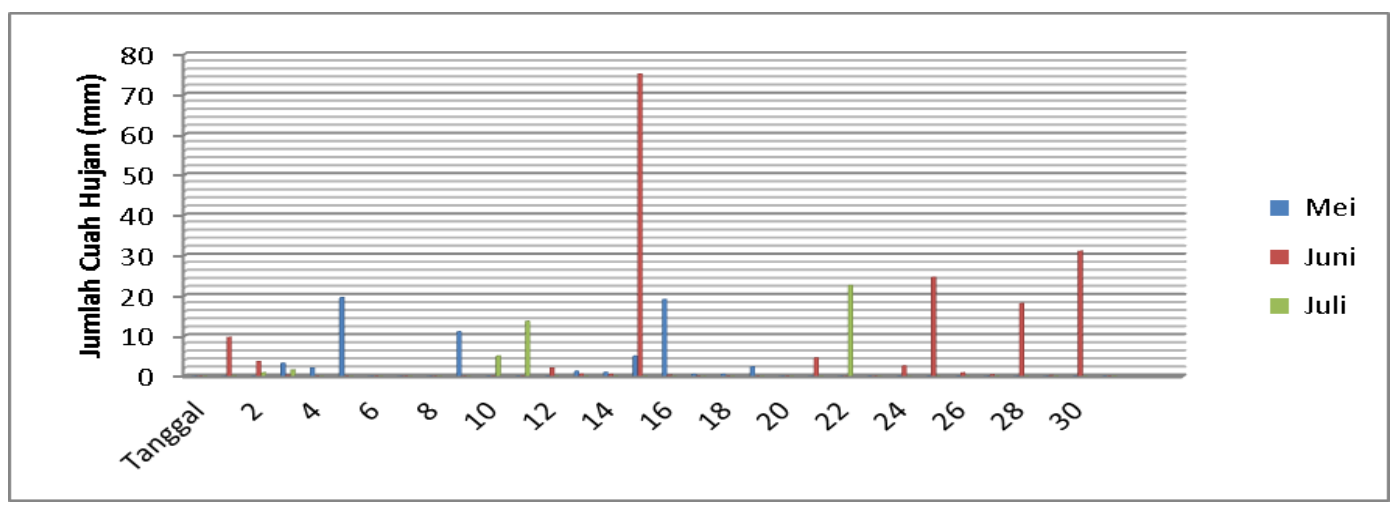

Gambar 4. Grafik Curah Hujan

Sumber: BMKG kenten Palembang 2018 


\section{Sistem Pola Tanam}

Sistem pola tanam adalah usaha penanaman pada sebidang lahan dengan mengatur susunan tata letak dan periode waktu tertentu termasuk pengelolaan tanah dan masa tidak ditanam selama periode tertentu. Maka pemilihan jenis/varietas yang ditanampun perlu disesuaikan dengan keadaan air yang tersedia ataupun curah hujan (Sari, 2017). Begitu pula pola tanam yang dilakukan di desa Mulya Sari kecamatan Tanjung Lago. Berdasarkan hasil wawancara dari petani bahwa didesa Mulya Sari mempunyai sistem pola tanam selama satu tahun dengan urutan padi, semangka dan jagung, urutannya sebagai berikut bulan November sampai Februari petak lahan ditanam dengan tanaman padi. Bulan April - Juni dibulan itu petani menamam tanaman semangka yang tidak begitu membutuhkan air. Dan untuk bulan Juli sampai September petak lahan ditanami tanaman Jagung. Pola tanam di desa Mulya Sari mengikuti ketersediaan air diwilayah tersebut dan jenis tanaman/varietas tanamam pun disesuaikan dengan jumlah kebutuhan air. Berdasarkan hasil perbandingan curuh hujan selama tiga tahun yaitu tatun 2016, 2017 dan 2018 (BMKG, 2018).

Pola tanam yang di lakukan di desa Mulya Sari adalah pola tanam Polikultur yaitu tumpang gilir (Multi Cropping), yaitu dilakukan secara beruntun sepanjang tahun dengan mempertimbangkan faktor-faktor lain untuk mendapat keuntungan maksimal (Sari, 2017).

\section{Pembahasan}

Pengelolaan tata air dilahan pasang surut gunanya untuk menjaga agar muka air di saluran maupun dipetak lahan dapat memenuhi kebutuhan tanaman, terpenuhi atau tidak karena dapat juga mempengaruhi pertumbuhan tanaman tersebut. Pengelolaan tata air, masyarakat petani menggunakan air untuk pengairan dengan meggunakan air disalurkan melalui saluran pedesaan (SPD). Di saluran SPD ini terdapat pintu air yang dapat mengatur ketersediaan air untuk setiap petak lahan. Dari saluran pedesaan lalu masuk ke saluran tersier selanjutnya setiap petak lahan mempunyai saluran kuarter atau saluran cacing yang di buat pada keliling setiap petak lahan. Pengairan dari tersier ke saluran cacing dihubungkan dengan pipa paralon dan juga dilengkapi dengan buka tutup untuk memasukkan dan mengeluarkan air ke lahan masing-masing. Bagi lahan yang sedang ditananami, maka saluran cacing atau saluran kuarter mereka buka guna untuk mengairi petaknya bila sudah sesuai dengan kebutuhan air maka pintu air saluran kuarter ditutup. Keguna saluran kuarter dan pintu air untuk mengatur air di petak lahan agar ketersediaan air di lahan terpenuhi dan tidak mengganggu petak lahan lain. Bila kebutuhan air terpenuhi pintu air kuarter akan ditutup,

Muka air saluran menunjukkan pergerakan air di saluran pedesaan dan saluran tersiar dengan tujuan untuk melihat bagaimana tinggi rendahnya muka air selama proses tanam di lahan pertanian rawa pasang surut. Berdasarkan pengukuran-pengukuran dasar elevasi muka air saluran di saluran SPD dan dua titik disaluran tersier dalam grafik tersebut menunjukan bahwa muka air saluran tidak pernah berada di atas titik elevasi dasar. Berarti bahwa tidak pernah terjadi luapan air di saluran tersier dan pengendalian pintu air di laksanakan sebaik mungkin oleh petani.

Berdasarkan data yang diperoleh muka air tanah tertinggi terjadi di bulan Mei yaitu $-16 \mathrm{~cm}$ sedangkan muka air tanah yang terendah terlihat pada bulan Juli yaitu $-108 \mathrm{~cm}$ dan $-110 \mathrm{~cm}$. Berdasarkan pengukuran Dasar elevasi 
muka air bahwa selama penelitian muka air tanah tidak ada yang mencapai dasar elevasi berarti disini tidak pernah terjadi luapan air di petak lahan. Dalam hal ini muka air tanah di petak lahan dapat dikendalikan dengan baik oleh para petani dengan menggunaka buka tutup pintu air, walaupun keadaan pintu air tidak otomatis.

Dari data muka air saluran dan muka air tanah tercatat bahwa menuunjukkan ketersdiaan air di saluran tersier dan kuarter seirama. Hal ini sesuai dengan Ngudiantoro 2009 bahwa Tinggi muka air di saluran tersier merupakan parameter utama dalam pengendalian muka air tanah di petak lahan, sebab perubahan muka air di saluran tersier akan menyebabkan perubahan muka air tanah di petak lahan dengan besaran yang sama, sedangkan curah hujan dan evapotranspirasi hanya memberikan pengaruh yang kecil terhadap kondisi muka air tanah di petak lahan.

Curah hujan pada kurun waktu tiga bulan ini cocok untuk tanaman semangka dengan hasil tanam yang cukup tinggi. Dalam waktu tersebutlah petani di desa Mulya Sari menanam semangka. Dengan hasil panen cukup banyak. Pada dua petak lahan, yang peneliti jadikan sempel penanaman semangka semua hasil dari penanaman semangka yaitu masingmasing 20 ton dan 24 ton per ha dalam satu kali penanaman dan tiga kali panen. Untuk tahun ini hasil panen semangka lebih baik dibandingkan tahun-tahun sebelumnya.

Pola tanam di desa Mulya Sari mengikuti ketersediaan air diwilayah tersebut dan jenis tanaman/varietas tanamam pun disesuaikan dengan jumlah kebutuhan air. Berdasarkan hasil perbandingan curuh hujan selama tiga tahun yaitu tatun 2016, 2017 dan 2018.( BMKG-Kenten). Pola tanam yang di lakukan di desa Mulya Sari adalah pola tanam Polikultur yaitu tumpang gilir (Multi
Cropping), yaitu dilakukan secara beruntun sepanjang tahun dengan mempertimbangkan faktor-faktor lain untuk mendapat keuntungan maksimal (Sari, 2017)

Jadi dalam pengamatan data mulai dari pengelolaan tata air, pengukuran fluktuasi muka air baik muka air saluran dan muka air petak lahann serta pola tanamm disesuaikan dengan ketersediaan air dan varietas yang dipilih. Maka dalam kurun waktu yang telah berjalan bahwa budidaya pertanian di desa Mulya Sari telah dapat meningkatakan produksi dan kesuburan tanah desa Mulya Sari. (Saragih, 2013) bahwa pengelolaan lahan rawa pasang surut yang dapat meningkatkan produktifitas (sustainable agricultural) juga dapat melestarikan kesuburan tanah sehingga pertanian berkelanjutan tercapai

\section{Kesimpulan}

Penelitian mengenai pengelolaan tata air lahan pertani rawa pasang surut sebagai upaya melestarikan lingkungan di Kecamatan Tanjung Lago Kabupaten Banyuasin ini menghasilkan kesimpulan sebagai berikut. Pertama, pengelolalaan tata air di lahan pertanian melalui beberapa saluran yaitu Saluran pedesaan (SPD) saluran Tersier dan Saluran Kuarter (Saluran Cacing) Walaupun pintu air tidak berfungsi otomatis tetapi tetap digunakan pintu air manual yang dikendalikan oleh para petani. Dengan pengaturan pintu air yang baik dari hasil perhitungan fluktuasi muka air saluran dan fluktuasi saluran muka air tanah menunjukan tidak pernah lewat dari dasar elevasi muka air, maka tidak pernah terjadi peluapan air baik di saluran atau di petak lahan. Kedua, upaya pelestari yang dilakukan adalah pengaturan tata air melalui saluran SDU, SPD, tersier dan saluran Kuarter atau saluran cacing, pola tanam dilakukan dengan cara polikultur komoditi budidaya yaitu penanamann dilakkan secara neruntun disesuaikan dengan kebutuhan air pada periode tanam. dengan pengelolaan tersebut maka lahan pasang 
surut dapat meningkatkan produktifitasnya juga dapat melestarikan kesuburan tanah sehingga pertanian berkelanjutan (sustainable agricultural) dapat dicapai.

Berdasarkan hasil penelitian mengenai pengelolaan tata air lahan pertani rawa pasang surut sebagai upaya melestarikan lingkungan di desa Mulya Sari Kecamatan Tanjung Lago Kabupaten Banyuasi, maka saran yang dapat diberikan antara lain. Pertama, penelitian ini masih banyak keterbatasan terutama berkaitan dengan variabel-variabel sebagai upaya pelestari lingkungan. Selanjutnya disarankan untuk meneliti variabel-variabel lain yang belum dikaji seperti teknologi yang digunakan dalam budidaya pertanian. Untuk instasi terkait agar dapat meninjau kembali daerah pertanian sebagai daerah pendukung ketahan pangan, dengan pengadaan pintu air sebagai salah satu pokok utama pengelolaan tata air di lahan pertanian.

\section{Daftar Pustaka}

Balai Besar Penelitian Tanaman Padi. (2016). Teknologi Tata Kelola Air Mikro Spesifik di Lahan Rawa. Retrieved from http://www.litbang.pertanian.go.id /berita/one/2662/
BMKG. (2018). Curah Hujan Kenten 2017 -2018. Palembang.

Ngudiantoro, Pawitan, H., Ardiansyah, M., Purwanto, M. Y. J., \& Susanto, R. H. (2009). Permodelan Fluktuasi Muka Air Tanah Untuk Mendukung Pengelolaan Air Pada Pertanian Lahan Rawa Pasang Surut Tipe A/B. Jurnal Matematika Sains Dan Teknologi, 10(2), 92-101.

Puspiastuti, R. (2012). Pengelolaan Tanah dan Air di Lahan Pasang Surut. Universitas Palang Karaya.

Saragih, S. (2013). Empat Kunci Sukses Pengelolaan Lahan Rawa Pasang Surut Untuk Usaha Pertanian Berkelanjutan. Retrieved from http://balittra.litbang.pertanian.go. id/index.php?option=com_content \&view=article\&id=1210:empatkunci-sukses-pengelolaan-lahanrawa-pasang-surut-untuk-usahapertanianberkelanjutan\&catid=13:infoaktual\&ltemid $=63$

Sari, M. D. (2017). Pengertian Dan Jenis Pola Taman. Retrieved from http://sumsel.litbang.pertanian.go. id/BPTPSUMSEL/beritapengertian-dan-jenis-polatanam.html. 